\title{
Elevated expression of the NLRP3 inflammasome in neutrophilic asthma
}

\author{
Jodie L. Simpson ${ }^{1,6}$, Simon Phipps ${ }^{2,3,6}$, Katherine J. Baines ${ }^{1}$, Kevin M. Oreo ${ }^{4}$, \\ Lakshitha Gunawardhana ${ }^{1}$ and Peter G. Gibson ${ }^{1,4,5}$
}

\begin{abstract}
Affiliations: 'Dept of Respiratory and Sleep Medicine, Centre for Asthma and Respiratory Diseases and Hunter Medical Research Institute, Faculty of Health, School of Medicine and Public Health, The University of Newcastle, Callaghan, ${ }^{2}$ School of Biomedical Sciences, The University of Queensland, Brisbane, ${ }^{3}$ Australian Infectious Diseases Research Centre, The University of Queensland, Brisbane, "Woolcock Institute of Medical Research, Sydney, and ${ }^{5}$ Dept of Respiratory and Sleep Medicine, John Hunter Hospital, New Lambton, Australia. ${ }^{6}$ Both authors contributed equally.
\end{abstract}

Correspondence: J.L. Simpson, Level 2, West Wing, Hunter Medical Research Institute, Locked Bag 1, Hunter Region Mail Centre, Newcastle, NSW 2310, Australia. E-mail: jodie.simpsonanewcastle.edu.au

ABSTRACT Asthma is a heterogeneous inflammatory airways disorder where interleukin (IL)-1 $\beta$ is thought to be a key mediator, especially in the neutrophilic subtype of asthma. The generation of active IL-1 $\beta$ requires proteolytic cleavage typically mediated through the formation of a caspase-1-containing inflammasome. This study hypothesised that an IL-1 $\beta$ endotype associated with the nucleotide-binding domain, leucine-rich repeat-containing family protein (NLRP)3/apoptosis-associated speck-like protein containing a caspase-recruitment domain (ASC)/caspase-1 inflammasome is characteristic of patients with the neutrophilic subtype of asthma.

Participants with asthma $(n=85)$ and healthy controls $(n=27)$ underwent clinical assessment, spirometry and sputum induction. Sputum was processed for differential cell count, gene expression and protein mediators. NLRP3 and caspase-1 expression was also determined by immunocytochemistry. Sputum macrophages were isolated $(n=8)$ and gene expression of NLRP3 and IL-1 $\beta$ determined.

There was significantly elevated gene expression of NLRP3, caspase- 1 , caspase- 4 , caspase- 5 and IL- $1 \beta$ in participants with neutrophilic asthma. Protein levels of IL-1 $\beta$ were significantly higher in those with neutrophilic asthma and correlated with sputum IL-8 levels. Sputum macrophages, as well as sputum neutrophils in neutrophilic asthma, expressed NLRP3 and caspase-1 protein.

NLRP3 inflammasome is upregulated in neutrophilic asthma and may regulate the inflammation process observed in this asthma phenotype through production of IL-1 $\beta$.

@ERSpublications

The NLRP3 inflammasome may be a key regulator of neutrophilic airway inflammation in asthma through production of IL-1/ http://ow.ly/t8HCe

This article has supplementary material available from www.erj.ersjournals.com

Received: June 202013 | Accepted after revision: Sept 092013 | First published online: Oct 172013

Support statement: This work was supported by National Health and Medical Research Council (NHMRC) (Canberra, Australia) project grants (grant number 631020) to J.L. Simpson and S. Phipps. J.L. Simpson holds the Australian Respiratory Council Ann Woolcock Research Fellowship. P. Gibson holds an NHMRC Practitioner Fellowship.

Conflict of interest: Disclosures can be found alongside the online version of this article at www.erj.ersjournals.com

Copyright @ERS 2014 


\section{Introduction}

Asthma is a complex disease with a heterogeneous inflammatory response that can be subtyped based on the presence of sputum granulocytes and T-helper cytokine responses [1,2]. This inflammatory subtyping has been effective in managing inhaled corticosteroid treatment and reducing exacerbations in eosinophilic asthma. While the mechanisms leading to eosinophilic inflammation in asthma have been extensively studied, little is known about noneosinophilic asthma, in particular the accumulation and responsiveness of neutrophils in the airways. The neutrophilic subtype of asthma has been identified in stable asthma [1], acute asthma exacerbations [3] and severe corticosteroid-dependent asthma [4]. A role for dysfunction of the innate immune system in neutrophilic asthma is hypothesised, where Toll-like receptor (TLR)2 activation is reported [5]; however, precise mechanisms and triggers are unclear. In a transcriptomic analysis, we identified that the interleukin (IL)-1 receptor and associated signalling intermediates were upregulated in neutrophilic asthma [6]. However, whether the pathways that promote the expression and maturation of IL-1 $\beta$ are altered in asthma remains poorly defined.

The synthesis of immature pro-IL- $1 \beta$ is induced by activation of innate immune receptors, such as the TLR and nucleotide-binding oligomerisation domain (NOD)-like receptor families, which sense conserved microbial motifs known as pathogen-associated molecular patterns. A second signal is required to induce the proteolytic cleavage of pro-IL- $1 \beta$ to its active, potent inflammatory form. This second signal can occur through the formation of a multisubunit complex called the "inflammasome", which is composed of a proinflammatory caspase(s), a nucleotide-binding domain, leucine-rich repeat-containing family (NLR) protein (NLRP) and the adaptor molecule, ASC (apoptosis-associated speck-like protein containing a caspase-recruitment domain) [7-9]. Mature IL-1 $\beta$ then activates the IL-1 receptor to induce the production of pro-inflammatory cytokines including IL-8, which is typically elevated in neutrophilic asthma [10].

The NLRP1, NLRP3, NLRC4 and AIM2 inflammasomes (absent in melanoma) all contain caspase-1, which is itself synthesised in an inactive form. In mice, caspase-11 is essential for caspase-1 activation [11], suggesting that the human orthologues of murine caspase-11, caspase- 4 and -5 , may synergise with the inflammasome complex to regulate caspase-1 activation [9]. The NLRP3 inflammasome is the most extensively characterised, and emerging data in humans and mice suggest that caspase- $4 / 5$ and caspase-11, respectively, contribute to NLRP3 inflammasome activation [12-14]. In human airways, a functional NLRP3 inflammasome has been identified in airway epithelial cells [15], and peripheral blood neutrophils express all components of the NLRP3 inflammasome, as well as IL-1 $\beta$ [16]; however, there is little data reporting the expression of NLRP3 inflammasome components in other cells from the airways in patients with asthma. A number of bacterial pathogens have been shown to require both TLR2 and inflammasome signalling to elicit the host immune response [17-19] and, while we have previously investigated the expression of TLR2 in asthma subtypes, the expression of inflammasome-associated proteins and IL- $1 \beta$ in asthma subtypes is unknown. This study hypothesised that an IL-1 $\beta$ endotype associated with the NLRP3/ ASC/caspase-1 inflammasome may underlie the phenotype of neutrophilic inflammation observed in patients with neutrophilic asthma.

\section{Methods}

\section{Study participants}

We studied nonsmoking adults with asthma $(n=85)$ from the Respiratory and Sleep Medicine Ambulatory Care Service at John Hunter Hospital (New Lambton, Australia) and healthy controls $(n=27)$ enrolled from the community by advertisement. Asthma was defined as physician-diagnosed asthma and a history of demonstrated airway hyperreactivity to hypertonic saline (a provocative dose causing a 15\% fall in forced expiratory volume in $1 \mathrm{~s}(\mathrm{FEV} 1)<15 \mathrm{~L})$ and/or a response to bronchodilator of $>12 \%$ or $>200 \mathrm{~mL}$. Participants gave written informed consent. The Hunter Area Health Service and University of Newcastle Research Human Ethics Committees approved this study.

\section{Study design}

Participants attended a single visit where symptoms, atopy, medication use and smoking status were assessed, and the spirometry and sputum induction were undertaken. Sputum was processed for inflammatory cell counts, gene expression and assessment of inflammatory protein in the supernatant and using immunocytochemistry. Further detail of smoking assessment, lung function and sputum processing is provided in the online supplementary material.

Sputum inflammatory subtypes

Participants were categorised as eosinophilic (sputum eosinophils $\geqslant 3 \%$ and sputum neutrophils $<61 \%$ ), neutrophilic (sputum neutrophils $\geqslant 61 \%$ and sputum eosinophils $<3 \%$ ) or paucigranulocytic asthma (sputum neutrophils $<61 \%$ and sputum eosinophils $<3 \%$ ) [20]. As there were only three participants with 
a mixed granulocytic inflammatory pattern of asthma (sputum neutrophils $\geqslant 61 \%$ and sputum eosinophils $\geqslant 3 \%$ ), these were not included in the analysis due to the small numbers.

Sputum gene expression

RNA was extracted, reverse transcribed to cDNA and real-time PCR was performed as previously described [6]. Results were calculated using $2^{-\Delta \Delta \mathrm{Ct}}$ (where $\mathrm{Ct}$ is the threshold cycle) relative to both the internal housekeeping gene (18S ribosomal RNA) and the mean $\Delta \mathrm{Ct}$ of the healthy control group.

Sputum supernatant mediator assessment

IL-1 $\beta$, IL-8 and neutrophil elastase (NE) were assessed using commercial assays (R\&D Systems, Minneapolis, MN, USA). The optimisation of IL-8 for sputum has been reported previously [21]. No effect of dithiothreitol was observed in any assay and recovery of spiked sputum samples were $>80 \%$ for IL- $1 \beta$.

\section{Sputum immunocytochemistry}

Cytospins were fixed in PLP fixative (3\% paraformaldehyde, L-lysine monohydrate, sodium m-periodate) [22], dried and coated in $15 \%$ sucrose before storage at $-20^{\circ} \mathrm{C}$. Thawed cytospins were washed, permeabilised (0.1\% Triton X-100; Sigma-Aldrich, St Louis, MO, USA) and blocked (1.5\% bovine serum albumin, 1.5\% donkey serum (Sigma-Aldrich), 0.1\% Triton X-100/PBS). Primary antibodies caspase-1 p10 (C-20) rabbit anti-human polyclonal (sc-515; Santa Cruz Biotechnology Inc., Santa Cruz, CA, USA), NE (clone NP57) mouse anti-human monoclonal (M0752; DakoCytomation, Glostrup, Denmark) and CIAS1/ NALP3 goat anti-human polyclonal (ab4207; Abcam plc., Cambridge, UK) were added followed by secondary donkey Alexa Fluor ${ }^{\circledR}$ antibodies matched for species (Life Technologies, Carlsbad, CA, USA). Primary antibody incubation was performed at $4{ }^{\circ} \mathrm{C}$ whilst secondary antibody incubations were performed at room temperature. Cells were mounted using ProLong Gold antifade reagent with 4,6-diamnio-2phenylindole (DAPI) (Life Technologies) for nuclear detection and stored at $4{ }^{\circ} \mathrm{C}$ protected from light. Slides were analysed on a Nikon Eclipse 90i Fluorescent Microscope and images were collected with NIS Elements software (Nikon Instruments Inc., Melville, NY, USA). Images were then merged using Image J (National Institutes of Health, Bethesda, MD, USA).

\section{Sputum IL-1 $\beta$ immunoblot}

Protein assessment was performed on thawed sputum supernatant using the ProStain Protein Quantification Kit (Active Motif Inc., Carlsbad, CA, USA). Sputum protein (5 $\mu \mathrm{g})$ was mixed with Laemmli sample buffer (Bio-Rad Laboratories, Hercules, CA, USA) and boiled for 10 min prior to SDS PAGE separation on pre-cast polyacrylamide gels (Mini-PROTEAN TGX Any kD Stain-Free Gels; Bio-Rad Laboratories). Separated proteins were transferred onto polyvinylidene difluoride (PVDF) membranes (Immobilon-P Membrane, PVDF, $0.45 \mu \mathrm{m}$; EMD Millipore Corporation, Billerica, MA, USA), blocked (5\% skimmed milk powder in Tris-buffered saline and Tween 20 (TBS-T) buffer) and incubated overnight with anti-IL-1 $\beta$ antibody (ab2105; Abcam plc.). Following washing, the membrane was incubated in anti-rabbit IgG conjugated to horseradish peroxidase (ab6721; Abcam plc.) at room temperature for $1 \mathrm{~h}$. Protein bands were detected using SuperSignal West Femto Maximum Sensitivity Substrate reagents (Thermo Fisher Scientific Inc., Waltham, MA, USA) on the ChemiDoc MP Imaging System (Bio-Rad Laboratories).

\section{Macrophage isolation from sputum}

Sputum macrophages were isolated via negative selection using magnetic cell separation with CD15 microbeads (Miltenyi Biotec, Sydney, Australia), LS cell separation columns and the VarioMACS system according to the manufacturer's instructions (Miltenyi Biotec).

\section{Analysis}

Data were analysed using Stata software version 11 (StataCorp, College Station, TX, USA). Results are reported as mean $\pm S D$ or median (interquartile range), unless otherwise indicated. Analysis was performed using the two-sample Wilcoxon's rank sum test, and the Kruskal-Wallis test was used for more than two groups. Fisher's exact test was used for categorical data. Multiple linear regression was conducted using a stepwise regression with significance level for removal from the model of $\mathrm{p}=0.100$ and significance level for addition to the model of $\mathrm{p}=0.050$. Variables were included in the model when $\mathrm{p}<0.250$ in univariate regression; age and sex were forced into the model. All results were reported as significant when $\mathrm{p}<0.05$ and $\mathrm{p}<0.008$ for post hoc testing in the four-group analysis.

\section{Results}

Participants with asthma of different inflammatory subtypes were similar in terms of age, sex and FEV $1 \%$ predicted. Those with noneosinophilic airway inflammation (neutrophilic and paucigranulocytic) tended to 
TABLE 1 Participant demographics and sputum inflammatory cell counts for participants with eosinophilic, neutrophilic or paucigranulocytic asthma and healthy controls

\begin{tabular}{|c|c|c|c|c|c|}
\hline & $\begin{array}{l}\text { Eosinophilic } \\
\text { asthma }\end{array}$ & $\begin{array}{l}\text { Neutrophilic } \\
\text { asthma }\end{array}$ & $\begin{array}{c}\text { Paucigranulocytic } \\
\text { asthma }\end{array}$ & Healthy controls & p-value \\
\hline Sex male/female $n$ & $17 / 13$ & $10 / 10$ & $21 / 14$ & 12/15 & 0.647 \\
\hline Ex-smoker n (\%) & 10 (33) & $8(40)$ & $14(40)$ & $3(11)$ & 0.052 \\
\hline $\begin{array}{l}\text { Smoking history } \\
\text { pack-years }\end{array}$ & $0.5(0.3-1.0)$ & $5.0(2.7-14.6)^{+}$ & $7.0(2.0-10.5)^{+}$ & $0.1(1.1-2.9)$ & 0.004 \\
\hline FEV $1 /$ FVC $\%$ & $68 \pm 11^{\oplus}$ & $59 \pm 11^{\tau+,+5}$ & $68 \pm 11^{\circ}$ & $82 \pm 7$ & $<0.001$ \\
\hline ICS dose & $1000(1000-2000)$ & $2000(\overline{800}-2000)$ & $2000(1000-2000)$ & & 0.531 \\
\hline $\begin{array}{l}\text { Total cells } \\
\quad \times 10^{6} \text { per } \mathrm{mL}\end{array}$ & $2.97(1.53-5.31)$ & $9.63(4.73-14.63) \top^{\oplus, \S,+}$ & $2.88(1.89-4.59)$ & $2.30(1.53-4.46)$ & $<0.001$ \\
\hline Viability \% & $74(65-84)$ & $91(83-94)^{\bullet, \S,+}$ & $71(55-81)$ & $67(58-81)$ & $<0.001$ \\
\hline Neutrophils \% & $27.1(18.3-36.3)$ & $81.6(68.8-90.1)^{\uparrow,+, \S}$ & $25.5(15.3-39.0)$ & $25.6(13.3-41.8)$ & $<0.001$ \\
\hline Macrophages \% & $52.0(41.3-69.5)$ & $15.3(8.6-22.2)^{\tau_{,}+, \S}$ & $66.7(48.0-76.3)$ & $64.8(47.8-75.5)$ & $<0.001$ \\
\hline $\begin{array}{l}\text { Macrophages } \\
\times 10^{4} \text { per } \mathrm{mL}\end{array}$ & $172(68.0-281)$ & 108 (67.5-228) & $164(119-296)$ & $131(81.9-268)$ & 0.137 \\
\hline Lymphocytes \% & 0.5 (0.3-1.3) & $0.5(0.0-1.0)^{\top}$ & $0.9(0.0-1.5)$ & $1.8(0.5-3.3)$ & 0.035 \\
\hline $\begin{array}{l}\text { Lymphocytes } \\
\times 10^{4} \text { per } \mathrm{mL}\end{array}$ & $1.6(0.7-4.3)$ & $2.7(0.0-7.4)$ & $2.4(0.0-5.5)$ & $3.2(1.3-8.4)$ & 0.465 \\
\hline $\begin{array}{l}\text { Columnar epithelial } \\
\text { cells } \%\end{array}$ & $3.1(0.8-5.8)$ & $1.4(0.0-3.4)$ & $4.8(1.0-6.5)$ & $2.8(1.0-12.8)$ & 0.093 \\
\hline $\begin{array}{l}\text { Columnar epithelial } \\
\text { cells } \times 10^{4} \text { per } \mathrm{mL}\end{array}$ & $6.7(3.9-17.3)$ & $8.2(0.0-21.9)$ & $2.7(0.0-8.3)$ & $4.5(2.4-11.3)$ & 0.533 \\
\hline Squamous $\%$ & $3.9(1.5-7.8)$ & $1.4(0.6-2.9)^{\#,+}$ & $2.9(1.0-11.9)$ & $5.7(2.0-8.5)$ & 0.041 \\
\hline
\end{tabular}

be older with greater smoking pack-years than the eosinophilic group (table 1). Reduced FEV1/forced vital capacity $\%$ along with increased total cells, and a reduced proportion of macrophages, were observed in those with neutrophilic asthma compared with the other three groups (table 1). All participants with asthma had sputum samples of good viability $(>40 \%)$.

\section{Inflammasome components}

Gene level expression for components of the NLRP3 inflammasome was higher in neutrophilic asthma. Specifically, NLRP3 expression was significantly higher in those with neutrophilic asthma compared with eosinophilic and paucigranulocytic asthma as well as healthy controls (fig. 1a). While highest in neutrophilic asthma, ASC gene expression was not different between the groups (fig. 1b). In order to examine this further, we then compared the NLRP3/ASC ratio and found that this was also significantly elevated in those with neutrophilic asthma compared with eosinophilic asthma, paucigranulocytic asthma and healthy controls (fig. 1c). Gene expression of the pro-inflammatory caspases, caspase-1, caspase- 4 and caspase-5, were significantly elevated in participants with neutrophilic asthma (fig. 1d-f).

IL-1 $\beta$ mRNA was assessed in 18 healthy controls and all 85 participants with asthma, and IL-1 $\beta$ protein levels were measured in eight healthy control, and 75 participants with asthma, due to the limited volumes of sputum supernatant available. Both gene expression and protein levels of IL-1 $\beta$ were elevated in those with neutrophilic asthma compared with eosinophilic asthma, paucigranulocytic asthma and healthy controls (fig. $2 \mathrm{a}$ and $\mathrm{b}$ ). We then confirmed the presence of the mature form of IL-1 $\beta$ in the supernatants of patients with neutrophilic asthma using Western blot (fig. 2c). 

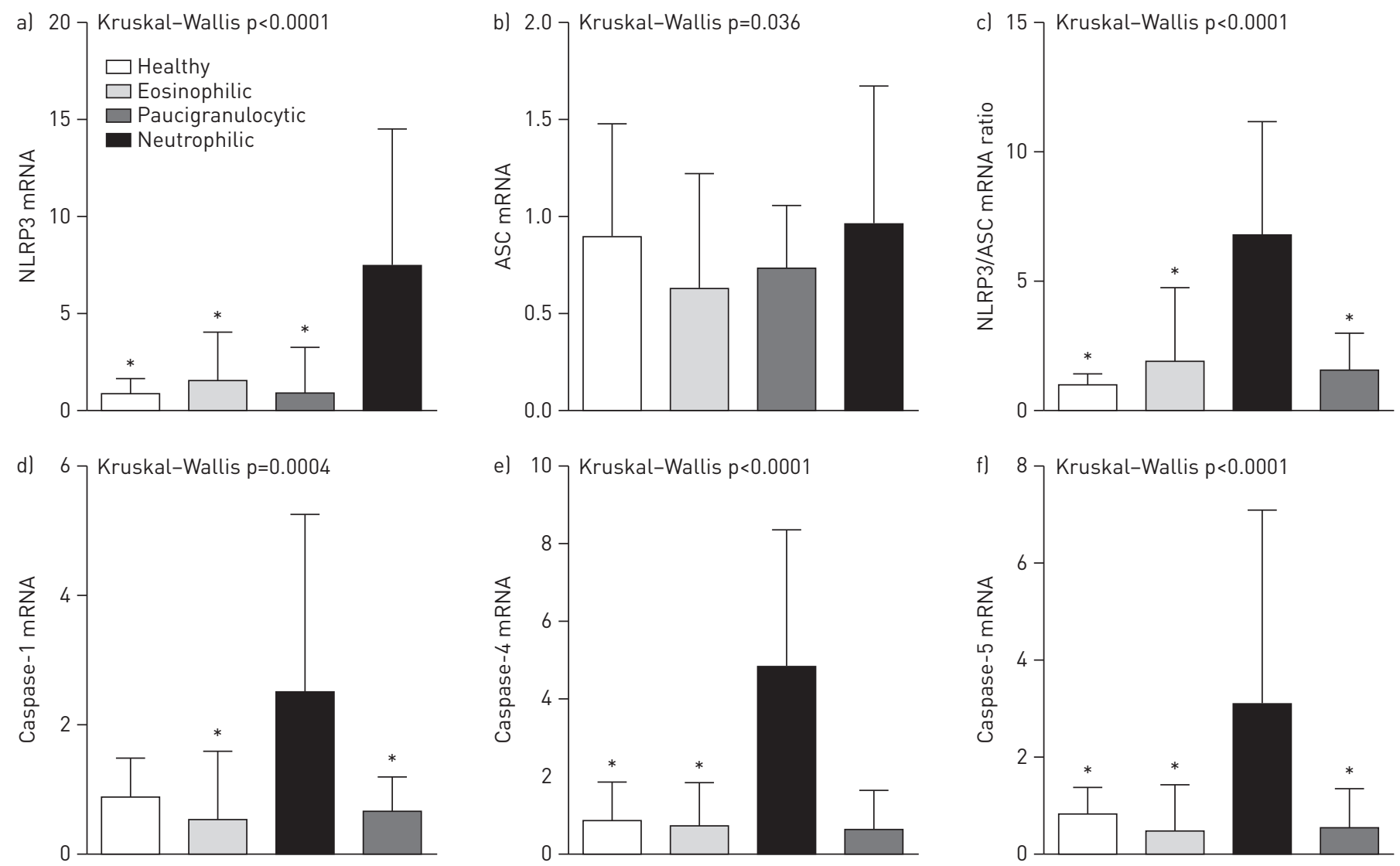

FIGURE 1 a) Nucleotide-binding domain, leucine-rich repeat-containing family protein (NLRP)3, b) apoptosis-associated speck-like protein containing a caspase-recruitment domain (ASC), c) NLRP3/ASC ratio, d) caspase-1, e) caspase-4 and f) caspase-5 gene expression for healthy controls, eosinophilic asthma, neutrophilic asthma and paucigranulocytic asthma. Bars represent median and error bars show the third quartile. ${ }^{*}$ : $<<0.05$ versus neutrophilic.

Next we assessed the expression of NLRP3 and caspase-1 in mixed sputum cells using immunocytochemistry. NE was used to clearly identify sputum neutrophils from eosinophils and macrophages. NLRP3 and caspase-1 immunoreactivity was observed in sputum macrophages from patients with all subtypes of asthma (fig. 3b-d). Sputum neutrophils were positive for NLRP3 in neutrophilic asthma (fig. 3a), while caspase-1 immunoreactivity of sputum neutrophils was detectable in both neutrophilic and eosinophilic asthma (fig. 3a and c).

\section{Inflammasome gene expression in isolated airway macrophages}

In a subset of samples (three neutrophilic and five paucigranulocytic asthma), sputum macrophages were isolated to a purity of $>90 \%$ using magnetic cell separation. Gene expression of IL- $1 \beta$ was significantly increased and NLRP3 was higher in isolated sputum macrophages in neutrophilic asthma (fig. 4).

\section{TLR and NOD2 expression and mediators of neutrophilic inflammation}

Gene expression for NOD2 and TLR2 was significantly higher in those with neutrophilic asthma, but no differences were observed between the patient groups for gene expression of TLR4 (table 2). Levels of mediators associated with neutrophilic inflammation (IL-8 and NE) were also highest in those with neutrophilic asthma (table 2).

\section{Associations of inflammasome components in patients with asthma}

Using stepwise multiple linear regression, the gene expression of NOD2, number of neutrophils and protein level of IL- 8 were significant predictors of sputum NLRP3 gene expression in asthma after correction for age and sex (table 3). The model included 69 data points and explained $>50 \%$ of the variation of NLRP3 gene expression $(\mathrm{p}<0.0001)$.

Furthermore, stepwise regression modelling showed that sputum gene expression of caspase- 1 and IL- $1 \beta$ and protein levels of IL- 8 were significant independent predictors of sputum supernatant IL- $1 \beta$ levels in patients with asthma (table 4). The model included 69 data points and explained $42 \%$ of the variance in 

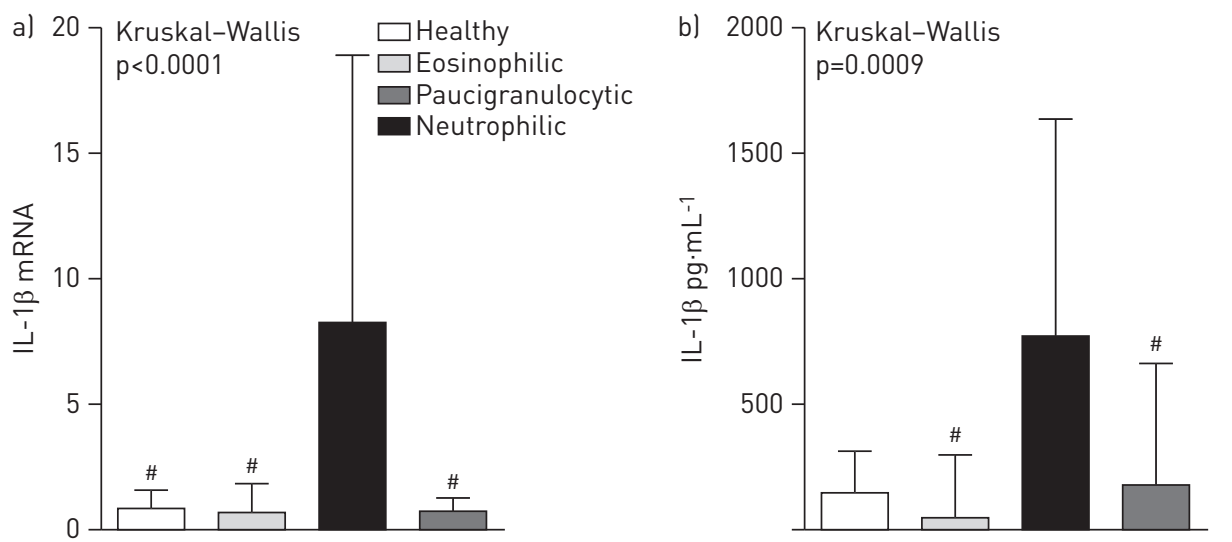

c)

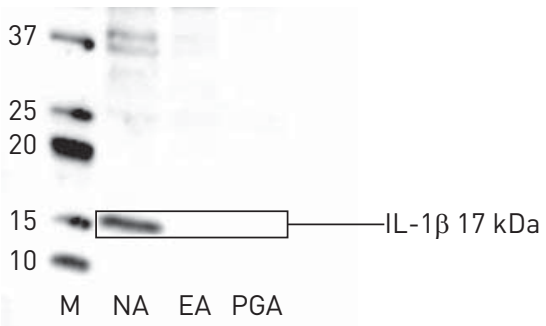

FIGURE 2 a) Sputum interleukin (IL)-1 $\beta$ gene expression and b) sputum IL-1 $\beta$ protein levels for healthy controls, eosinophilic asthma, neutrophilic asthma and paucigranulocytic asthma. Bars represent median and error bars show the third quartile. c) Representative Western blot image showing $17-\mathrm{kDa}$ mature IL-1 $\beta$ observed in neutrophilic asthma (NA). M: molecular weight marker; EA: eosinophilic asthma; PGA: paucigranulocytic asthma. ${ }^{\#}: \mathrm{p}<0.008$ versus neutrophilic.

sputum IL-1 $\beta$ and was highly significant $(\mathrm{p}<0.0001)$. Scatter plots for IL-1 $\beta$ gene expression and IL-8 protein with IL-1 $\beta$ protein are shown in figure 5 .

\section{Discussion}

In this study, we have shown that patients with neutrophilic asthma have augmented expression of key inflammasome components and increased release of IL- $1 \beta$ protein. This is the first study to implicate the inflammasome in neutrophilic asthma. Gene expression was significantly elevated for NLRP3, caspase-1 and IL- $1 \beta$. In addition, gene expression of both caspase- 4 and -5 was also significantly elevated in participants with neutrophilic asthma. Sputum supernatant IL-1 $\beta$ protein levels were significantly higher in those with neutrophilic asthma compared with other asthma subtypes and the mature form of IL-1 $\beta$ was identified in
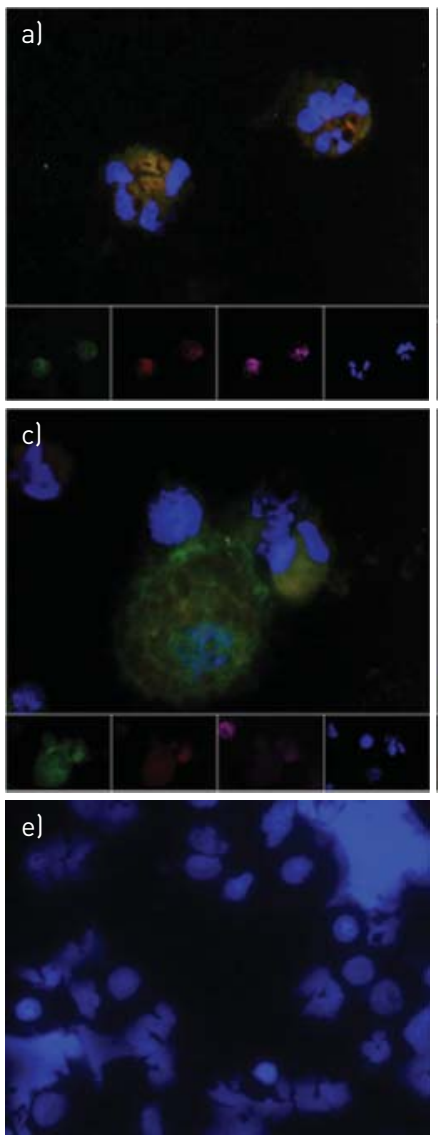
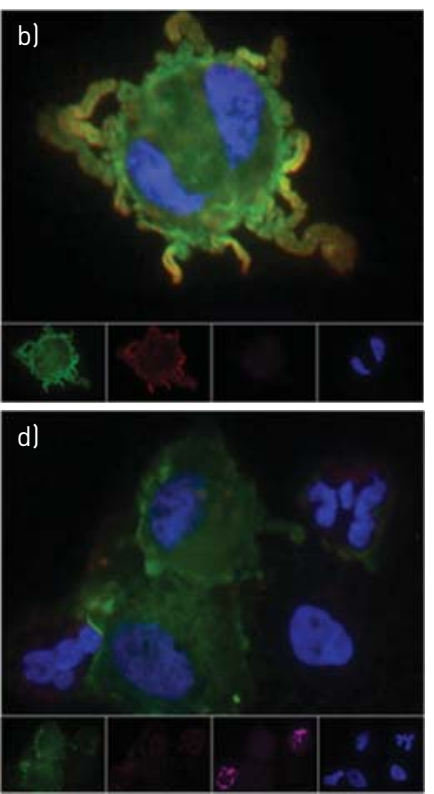

Caspase-1

NLRP3

Neutrophil elastase

Nuclear DAPI
FIGURE 3 Sputum immunocytochemistry images. a) Sputum neutrophils from a patient with neutrophilic asthma, b) sputum macrophage from a patient with neutrophilic asthma, c) sputum macrophages and neutrophils from a patient with eosinophilic asthma, and d) sputum macrophage and neutrophil from a patient with paucigranulocytic asthma. e) Secondary control image. NLRP: nucleotidebinding domain, leucine-rich repeatcontaining family protein; DAPI: 4,6-diamino-2-phenylindole. 

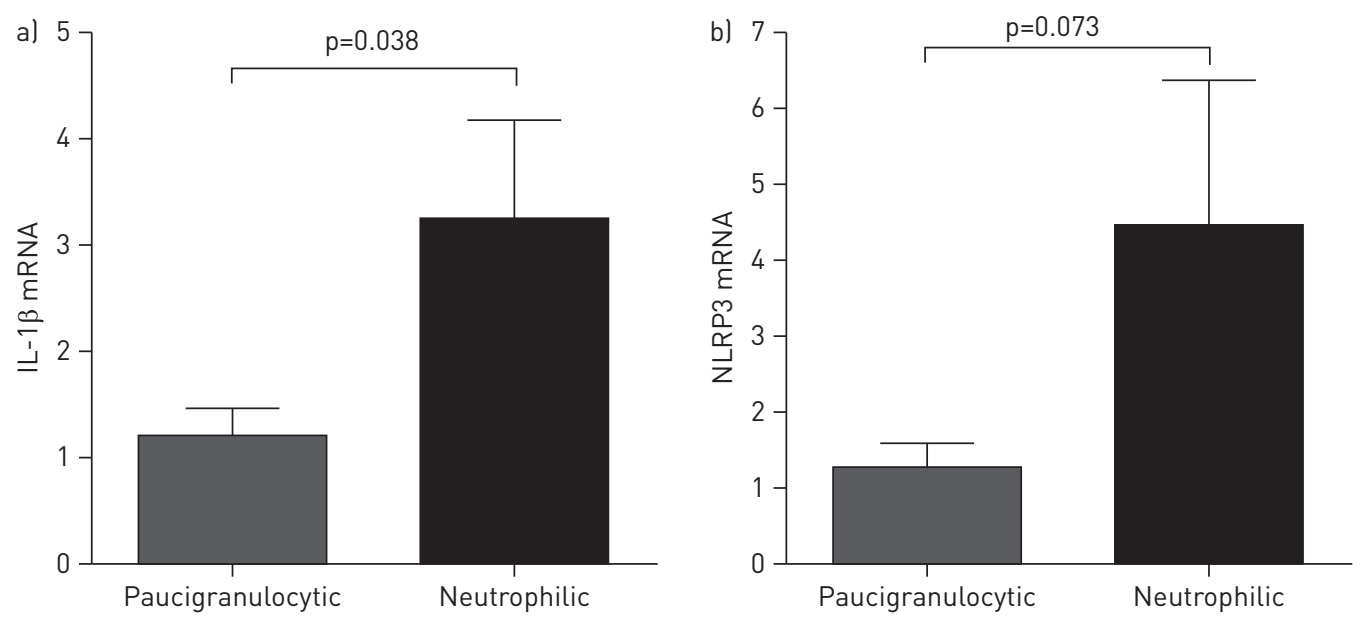

FIGURE 4 Gene expression of a) interleukin (IL)-1 $\beta$ and b) nucleotide-binding domain, leucine-rich repeat-containing family protein (NLRP)3 is increased in isolated sputum macrophages in neutrophilic asthma compared with paucigranulocytic asthma.

the sputum supernatant of patients with neutrophilic asthma. The expression of other innate pattern recognition receptors that promote the synthesis of pro-IL-1 $\beta$ (signal 1), including NOD2 and TLR2, was also significantly elevated in sputum cells from patients with neutrophilic asthma. Proteins for NLRP3 and caspase- 1 were expressed in sputum macrophages in all asthma subtypes, but there was also expression in neutrophils from patients with neutrophilic asthma.

Interest in the NLRP inflammasomes has increased over recent years, but little is understood about the role of inflammasome activation in the airways of patients with asthma and, in particular, those with neutrophilic asthma have not been reported previously. Our understanding of the role of inflammasome activation in human asthma is limited by the small number of studies using clinical samples. A recent study has shown that the NLPR3 inflammasome mediated the neutrophilic airway inflammation induced by particles with a 50\% cut-off aerodynamic diameter of $10 \mu \mathrm{m}$ [15], demonstrating that nonmicrobial triggers can influence the accumulation of neutrophils in the airway. Infections such as Chlamydophila pneumoniae and respiratory syncytial virus (which also result in neutrophilic bronchitis) induce NLRP3 inflammasomemediated IL- $1 \beta$ release $[23,24]$. A recent small study of patients with mild asthma $(n=7)$ who had normal lung function showed reduced gene expression from healthy volunteers for ASC, caspase-1 and IL-1 $\beta$ [25]. A possible reason for this may be the small numbers studied and the presence of very mild disease. Our patients had moderate to severe disease (mean $\mathrm{FEV}_{1} \%$ predicted was $71.5 \%$ ), and neutrophil and eosinophil numbers were up to 10 times higher than those reported by BRICKEY et al. [25], suggesting that a more intense and active inflammatory process is occurring.

TABLE 2 NOD2 and TLR gene expression and inflammatory protein expression for participants with eosinophilic, neutrophilic and paucigranulocytic asthma and healthy controls

\begin{tabular}{|c|c|c|c|c|c|}
\hline & $\begin{array}{l}\text { Eosinophilic } \\
\text { asthma }\end{array}$ & $\begin{array}{l}\text { Neutrophilic } \\
\text { asthma }\end{array}$ & $\begin{array}{c}\text { Paucigranulocytic } \\
\text { asthma }\end{array}$ & Healthy controls & p-value \\
\hline \multicolumn{6}{|l|}{ Gene expression } \\
\hline TLR2 mRNA & $1.29(0.55-3.52)$ & $8.59(4.46-17.61)^{\bullet,+, \S}$ & $2.74(0.67-7.57)$ & $0.86(0.39-2.40)$ & $<0.001$ \\
\hline TLR4 mRNA & $0.78(0.26-2.45)$ & $2.48(1.01-6.81)$ & $1.19(0.35-5.02)$ & $0.71(0.51-2.57)$ & 0.070 \\
\hline \multicolumn{6}{|l|}{ Protein level } \\
\hline $\mathrm{NE} n g \cdot \mathrm{mL}^{-1}$ & 414.6 (240-1086) & $2995(529-9188)^{\tau_{+,+, \S}}$ & 521.7 (189-845) & $493(110-678)$ & 0.001 \\
\hline NE samples $n$ & 28 & 16 & 29 & 13 & \\
\hline
\end{tabular}

Data are presented as median (interquartile range), unless otherwise stated. NOD: nucleotide-binding oligomerisation domain-containing protein; TLR: Toll-like receptor; IL: interleukin; NE: neutrophil elastase. ${ }^{\#}$ : for four-group comparison; ${ }^{\natural}: \mathrm{p}<0.008$ versus paucigranulocytic asthma; ${ }^{+}: \mathrm{p}<0.008$ versus eosinophilic asthma; ${ }^{\S}: \mathrm{p}<0.008$ versus healthy controls. 
TABLE 3 Multivariate linear regression outcomes with dependent variable sputum NLRP3 gene expression

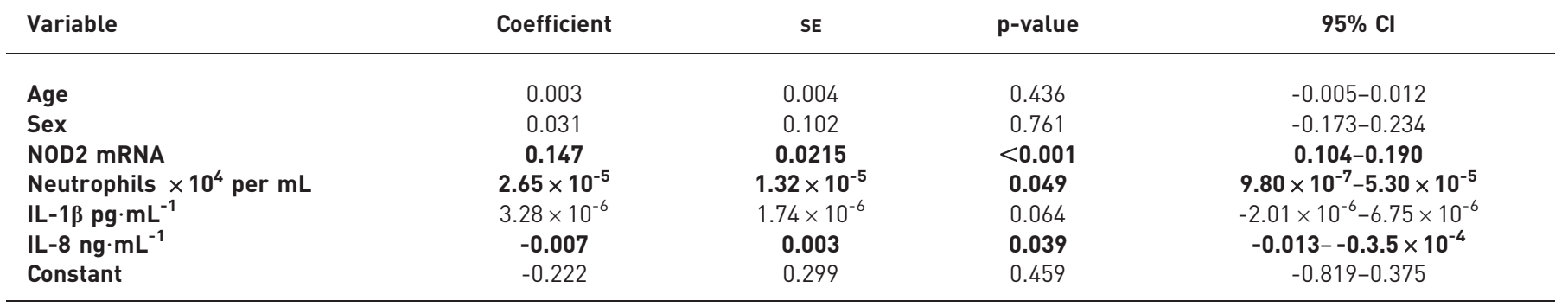

NLRP: nucleotide-binding domain, leucine-rich repeat-containing family protein; NOD: nucleotide-binding oligomerisation domain-containing protein; IL: interleukin. Values in bold are statistically significant.

In addition to caspase-1, we also observed that gene expression for caspase- 4 and -5 was significantly elevated in neutrophilic asthma but not the other asthma subtypes. In mice, caspase-11 (orthologous to human caspase- 4 and -5) has been shown to contribute to NLRP3/caspase-1-induced IL-1 $\beta$ secretion [14], while in humans, caspase- 4 has been shown to associate with the NLRP1 and NLRP3 inflammasomes to activate procaspase- 1 and pro-IL-1 $\beta[12,26]$. These data, along with our increased gene expression for caspase- 4 and caspase-5 in neutrophilic asthma, suggest an important role for these caspases in airway disease.

Inflammasome formation can be triggered by various microbial and host-derived factors, including uric acid crystals, silica and reactive oxygen species. The trigger(s) that result in NLRP3 inflammasome formation in asthma remain elusive. However, we have previously reported increased bacterial colonisation in neutrophilic asthma, as well as increased levels of 8-isoprostane, a marker of oxidative stress associated with sputum neutrophils and bacterial colonisation, suggesting both reactive oxygen species and resident airway pathogenic bacteria are potential triggers for the formation of the inflammasome and subsequent IL-1 $\beta$ production $[5,27]$.

IL- $1 \beta$ is a potent inflammatory cytokine implicated in a number of chronic inflammatory diseases, including asthma and chronic obstructive pulmonary disease, and we have recently reported overexpression of genes from the IL-1 pathway in the neutrophilic subtype of asthma [6]. Extending this, we found both supernatant levels and mRNA expression of IL-1 $\beta$ were significantly elevated in those with neutrophilic asthma compared with other asthma subtypes and healthy controls, suggesting a key role for IL-1 $\beta$ in the neutrophilic asthma. Sputum IL-1 $\beta$ levels were independently associated with the neutrophil chemoattractant IL-8 after correcting for age, sex and neutrophil number. Our results support recent findings, which show increased IL-1 $\beta$ in asthma, especially in severe asthma [28] and, in particular, in neutrophilic severe asthma [29], and provide evidence of the involvement of the NLRP3 inflammasome.

The gene expression levels of NOD2 and TLR2 were also significantly elevated in sputum cells from patients with neutrophilic asthma, and the colocalisation of immunoreactive NLRP3 and caspase-1 in sputum cells (signal 2), together with the elevated sputum IL-1 $\beta$ levels, supports the notion that the NLRP3 inflammasome is activated in neutrophilic asthma. The activation of TLR2 or NOD2 and subsequent NLRP3 activation is not dissimilar to the "multiple hits" hypothesis initially proposed by PAVORD et al. [30] in severe refractory asthma, where multiple points of stimulation can occur to the immune system, resulting in more severe airways disease.

TABLE 4 Multivariate linear regression outcomes with dependent variable sputum supernatant interleukin (IL)-1 $\beta$ levels

\begin{tabular}{lcccc} 
Variable & Coefficient & SE & p-value & $\mathbf{9 5 \%}$ CI \\
\hline Age & $9.19 \times 10^{-6}$ & 0.006 & 0.988 & $-0.012-0.012$ \\
Sex & -0.0590 & 0.150 & 0.695 & $-0.358-0.240$ \\
TLR2 mRNA & 0.016 & 0.009 & 0.075 & $-0.002-0.034$ \\
Caspase-1 mRNA & $\mathbf{0 . 1 2 1}$ & $\mathbf{0 . 0 4 9}$ & $\mathbf{- 0 . 2 2 0 - - 0 . 0 2 3}$ \\
IL-1 $\beta$ mRNA & $\mathbf{0 . 0 1 8}$ & $\mathbf{0 . 0 0 6}$ & $\mathbf{0 . 0 1 7}$ & $\mathbf{0 . 0 0 5 - 0 . 0 3 0}$ \\
IL-8 $\mathbf{n g} \cdot \mathrm{mL}^{-1}$ & $\mathbf{0 . 0 1 6}$ & $\mathbf{0 . 0 0 2}$ & $\mathbf{0 . 0 0 6}$ & $\mathbf{0 . 0 1 1 - 0 . 0 2 1}$ \\
Constant & 0.323 & 0.452 & 0.478 & $-0.851-1.228$ \\
\hline
\end{tabular}

TLR: Toll-like receptor. Values in bold are statistically significant. 

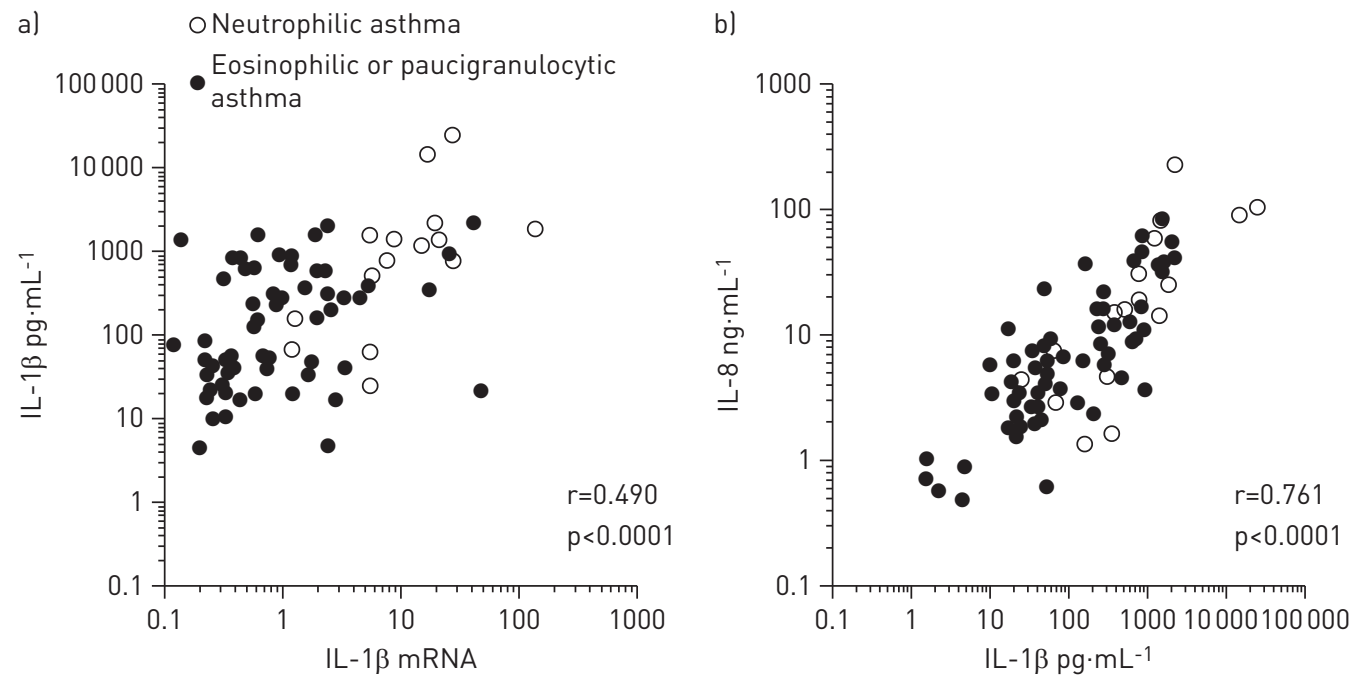

FIGURE 5 Scatter plots of independent predictors of sputum interleukin (IL)-1 $\beta$ protein levels as a) IL-1 $\beta$ mRNA and b) IL-8 protein.

We studied the sputum cell expression of NLRP3 and caspase-1 using immunocytochemistry and show that airway macrophages from patients with asthma, irrespective of inflammatory subtype, stained positive for both proteins. Interestingly, neutrophils from the patient with neutrophilic asthma (but not other phenotypes) also stained strongly for both NLRP3 and caspase-1. This suggests that the differences between asthma phenotypes in inflammasome activation may be driven by the contribution of both neutrophil and macrophage inflammasome expression. The importance of the neutrophil NLRP3 inflammasome has been recently shown by MANKAN et al. [16], where they show a functional NLRP3 inflammasome in neutrophils, while others have shown that genetic variations in NLRP3 result in delayed apoptosis of neutrophils, which influences the resolution of inflammation [31]. Further work is required to elucidate the specific contribution of the neutrophil inflammasome to asthma.

The cross-sectional nature of the study is a limitation in allowing the cause and/or effect to be determined and further research is necessary to establish this. The majority of participants in this study with asthma were taking high doses of inhaled corticosteroids and it is, therefore, not possible to examine the influence that inhaled corticosteroids may be having on the expression of innate immune genes in asthma. However, despite the frequent use of inhaled corticosteroids in all subtypes of asthma, we still observed significant differences in NLRP3 receptor expression between asthma phenotypes. We have investigated the expression of the NLRP3 inflammasome and IL-1 $\beta$ using the noninvasive method of sputum induction; however, the results of this study may not represent those in the airway tissue and this is an area for further study.

In conclusion, we have shown the presence of increased gene expression for the NLRP3 inflammasome in mixed sputum cells from patients with neutrophilic asthma and have further demonstrated the presence of NLRP3 and caspase-1 protein in both sputum macrophages and neutrophils in neutrophilic asthma. Upregulation of NLRP3 inflammasome occurs in asthma and, in particular, in the neutrophilic phenotype where there is evidence of two or more innate signals, including NLRP3, TLR2 and NOD2. Sputum IL-1 $\beta$ protein levels were independently associated with sputum IL-8 levels suggesting a relationship with neutrophil recruitment and activation.

\section{Acknowledgements}

The authors would like to acknowledge the technical assistance of M. Tooze, C. Garside, N. Bell, H. Candler, N. Fibbens, K. Fakes, B. Ridewood and R. Oldham (Dept of Respiratory and Sleep Medicine, Centre for Asthma and Respiratory Diseases and Hunter Medical Research Institute, Faculty of Health, School of Medicine and Public Health, The University of Newcastle, Callaghan, Australia).

\section{References}

1 Simpson JL, Scott R, Boyle MJ, et al. Inflammatory subtypes in asthma: assessment and identification using induced sputum. Respirology 2006; 11: 54-61.

2 Woodruff PG, Modrek B, Choy DF, et al. T-helper type 2-driven inflammation defines major subphenotypes of asthma. Am J Respir Crit Care Med 2009; 180: 388-395.

3 Wark PA, Johnston SL, Simpson JL, et al. Chlamydia pneumoniae immunoglobulin A reactivation and airway inflammation in acute asthma. Eur Respir J 2002; 20: 834-840. 
Simpson JL, Powell H, Boyle MJ, et al. Clarithromycin targets neutrophilic inflammation in refractory asthma. Am J Respir Crit Care Med 2008; 177: 148-155.

5 Simpson JL, Grissell TV, Douwes J, et al. Innate immune activation in neutrophilic asthma and bronchiectasis. Thorax 2007; 62: 211-218.

6 Baines KJ, Simpson JL, Wood LG, et al. Transcriptional phenotypes of asthma defined by gene expression profiling of induced sputum samples. J Allergy Clin Immunol 2011; 127: 153-160.

7 Meylan E, Tschopp J, Karin M. Intracellular pattern recognition receptors in the host response. Nature 2006; 442: 39-44.

8 Martinon F, Tschopp J. Inflammatory caspases: linking an intracellular innate immune system to autoinflammatory diseases. Cell 2004; 117: 561-574.

9 Martinon F, Tschopp J. Inflammatory caspases and inflammasomes: master switches of inflammation. Cell Death Differ 2007; 14: 10-22.

10 Gibson PG, Simpson JL, Saltos N. Heterogeneity of airway inflammation in persistent asthma. Chest 2001; 119: $1329-1336$.

11 Wang S, Miura M, Jung YK, et al. Murine caspase-11, an ICE-interacting protease, is essential for the activation of ICE. Cell 1998; 92: 501-509.

12 Sollberger G, Strittmatter GE, Kistowska M, et al. Caspase-4 is required for activation of inflammasomes. J Immunol 2012; 188: 1992-2000.

13 Kayagaki N, Warming S, Lamkanfi M, et al. Non-canonical inflammasome activation targets caspase-11. Nature 2011; 479: 117-121.

14 Rathinam VA, Vanaja SK, Waggoner L, et al. TRIF licenses caspase-11-dependent NLRP3 inflammasome activation by Gram-negative bacteria. Cell 2012; 150: 606-619.

15 Hirota JA, Hirota SA, Warner SM, et al. The airway epithelium nucleotide-binding domain and leucine-rich repeat protein 3 inflammasome is activated by urban particulate matter. J Allergy Clin Immunol 2012; 129: 1116-1125.

16 Mankan AK, Dau T, Jenne D, et al. The NLRP3/ASC/caspase-1 axis regulates IL-1 $\beta$ processing in neutrophils. Eur J Immunol 2012; 42: 710-715.

17 Jones CL, Weiss DS. TLR2 signaling contributes to rapid inflammasome activation during F. novicida infection. PLoS One 2011; 6: e20609.

18 Lee HM, Yuk JM, Kim KH, et al. Mycobacterium abscessus activates the NLRP3 inflammasome via Dectin-1-Syk and p62/SQSTM1. Immunol Cell Biol 2011; 90: 601-610.

19 Shimada K, Crother TR, Karlin J, et al. Caspase-1 dependent IL-1 $\beta$ secretion is critical for host defense in a mouse model of Chlamydia pneumoniae lung infection. PLoS One 2011; 6: e21477.

20 Simpson JL, McElduff P, Gibson PG. Assessment and reproducibility of non-eosinophilic asthma using induced sputum. Respiration 2010; 79: 147-151.

21 Simpson JL, Scott RJ, Boyle MJ, et al. Differential proteolytic enzyme activity in eosinophilic and neutrophilic asthma. Am J Respir Crit Care Med 2005; 172: 559-565.

22 Hoshi H, Ohno I, Honma M, et al. IL-5, IL-8 and GM-CSF immunostaining of sputum cells in bronchial asthma and chronic bronchitis. Clin Exp Allergy 1995; 25: 720-728.

23 Eitel J, Meixenberger K, van Laak C, et al. Racl regulates the NLRP3 inflammasome which mediates IL-1 $\beta$ production in Chlamydophila pneumoniae infected human mononuclear cells. PLoS One 2012; 7: e30379.

24 Segovia J, Sabbah A, Mgbemena V, et al. TLR2/MyD88/NF- $\kappa$ B pathway, reactive oxygen species, potassium efflux activates NLRP3/ASC inflammasome during respiratory syncytial virus infection. PLoS One 2012; 7: e29695.

25 Brickey WJ, Alexis NE, Hernandez ML, et al. Sputum inflammatory cells from patients with allergic rhinitis and asthma have decreased inflammasome gene expression. J Allergy Clin Immunol 2011; 128: 900-903.

26 Martinon F, Burns K, Tschopp J. The inflammasome: a molecular platform triggering activation of inflammatory caspases and processing of proIL- $\beta$. Mol Cell 2002; 10: 417-426.

27 Wood LG, Simpson JL, Hansbro P, et al. Potentially pathogenic bacteria cultured from the sputum of stable asthmatics are associated with increased 8-isoprostane and airway neutrophilia. Free Radic Res 2010; 44: 146-154.

28 Tillie-Leblond I, Pugin J, Marquette CH, et al. Balance between proinflammatory cytokines and their inhibitors in bronchial lavage from patients with status asthmaticus. Am J Respir Crit Care Med 1999; 159: 487-494.

29 Hastie AT, Moore WC, Meyers DA, et al. Analyses of asthma severity phenotypes and inflammatory proteins in subjects stratified by sputum granulocytes. J Allergy Clin Immunol 2010; 125: 1028-1036.

30 Pavord ID, Birring SS, Berry M, et al. Multiple inflammatory hits and the pathogenesis of severe airway disease. Eur Respir J 2006; 27: 884-888.

31 Blomgran R, Patcha Brodin V, Verma D, et al. Common genetic variations in the NALP3 inflammasome are associated with delayed apoptosis of human neutrophils. PLoS One 2012; 7: e31326. 